Check for updates

Cite this: RSC Adv., 2018, 8, 27703

Accepted 30th July 2018

DOI: $10.1039 / \mathrm{c} 8 \mathrm{ra0} 2229 \mathrm{~h}$

rsc.li/rsc-advances

\section{One-pot synthesis of end-functionalised soluble star-shaped polymers by living ring-opening metathesis polymerisation using a molybdenum- alkylidene catalyst $\uparrow$}

\author{
Zelin Sun and Kotohiro Nomura iD *
}

Precise synthesis of soluble star-shaped polymers has been achieved by adopting living ring-opening metathesis polymerisation (ROMP) using a molybdenum-alkylidene catalyst with sequential addition of norbornene and cross-linking agent; the method provides efficient one-pot synthesis of high molecular weight end-functionalised star-shaped polymers $\left(M_{n}=>1.37 \times 10^{5}\right)$ with more arms (branching) with rather low PDI values $\left(M_{w} / M_{n}=1.17-1.37\right)$ under the optimised conditions.

\section{Introduction}

Star polymers containing multiple linear arms connected at a central branched core are one of the simplest nonlinear polymers, ${ }^{\mathbf{1 - 1 0}}$ and development of precise synthesis methods by living polymerisation techniques attracts considerable attention. ${ }^{1-10}$ Reported examples for the synthesis by adopting living ring-opening metathesis polymerisation (ROMP) ${ }^{11-23}$ via arm (brush) first ${ }^{24-30}$ and core first (in-out) ${ }^{31-35}$ approaches by sequential addition of monomers/cross linkers (CLs) are known. Moreover, related examples for synthesis of cross-linked polymers (which are insoluble in common organic solvents) by ROMP are also known, ${ }^{36-39}$ especially in terms of application as monolith materials for separation. In particular, the approach by the sequential living ROMP of norbornene (NBE) and crosslinking reagent $(1,4,4 \mathrm{a}, 5,8,8 a$-hexahydro- $1,4,5,8$-exo-endodimethano-naphthalene, CL) using a Mo-alkylidene catalyst enables us to introduce functionality to the polymer chain ends (star surface) through cleavage of the polymer-metal double bonds with aldehyde via Wittig-type reaction. ${ }^{15,23,31-34,40-42}$ However, the previous reports ${ }^{31-34}$ adopting the so called Method 1 (shown in Scheme 1) only demonstrated synthesis of soluble polymers with a small number of arms under limited conditions ( 5 or 10 equiv. of CL, ${ }^{31-34}$ shown below in Table 1 ) due to the difficulty of molecular weight control, as also described below.

We thus herein demonstrate that the protocols for synthesis of soluble high molecular weight end-functionalised starshaped polymers with more arms (branching) have been

Department of Chemistry, Faculty of Science, Tokyo Metropolitan University, 1-1 Minami Osawa, Hachioji, Tokyo 192-0397, Japan

$\dagger$ Electronic supplementary information (ESI) available. See DOI: 10.1039/c8ra05229h developed by using the living ROMP technique under the carefully optimised conditions. ${ }^{43}$ The synthetic protocols should contribute to providing new (or improved) properties by placement of more functionalities on the star surface.

\section{Results and discussion, experimental}

As reported previously, ${ }^{31-34}$ the method consists of 4 steps by sequential addition of NBE, CL, NBE, and the termination by addition of aldehyde (Scheme 1). In order to obtain the starshaped polymers with more arms (branching), two approaches especially at the core formation step (2nd reaction

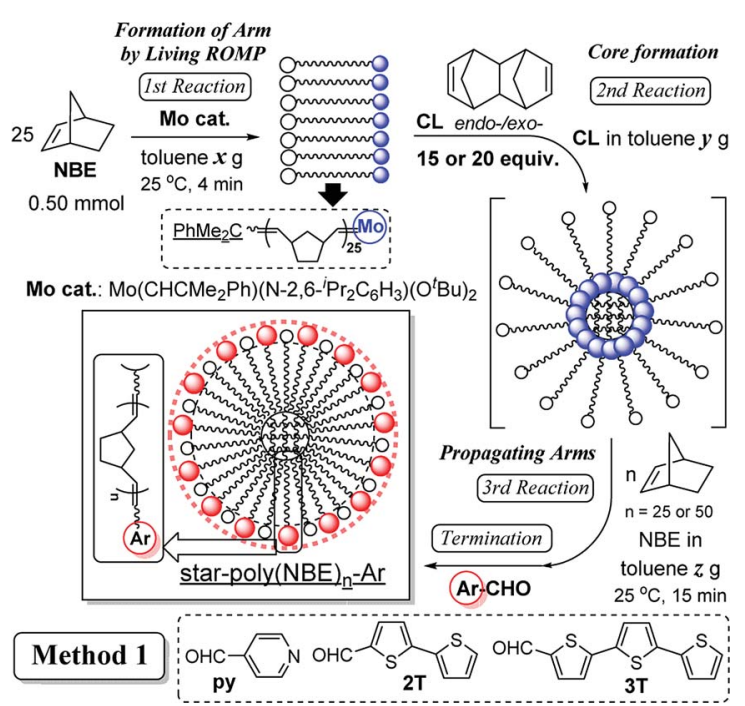

Scheme 1 Synthesis of star-shaped ROMP polymers by sequential addition of norbornene (NBE) and cross-linker $(\mathrm{CL})$ in the presence of molybdenum-alkylidene catalyst (Mo cat.). 
Table 1 Synthesis of star-shaped polymers by living ring-opening metathesis polymerisation (ROMP) using $\mathrm{Mo}\left(\mathrm{CHCMe}_{2} \mathrm{Ph}\right)\left(\mathrm{N}-2,6^{-}{ }^{\mathrm{i}} \mathrm{Pr}{ }_{2} \mathrm{C}_{6}{ }^{-}\right.$ $\left.\mathrm{H}_{3}\right)\left(\mathrm{O}^{t} \mathrm{Bu}\right)_{2}(\text { Method } 1)^{a}$

\begin{tabular}{|c|c|c|c|c|c|c|c|c|c|}
\hline \multirow[b]{2}{*}{ Run } & \multirow{2}{*}{$\frac{\text { Toluene }^{b} / \mathrm{g}}{x / y / z}$} & \multicolumn{3}{|l|}{ 2nd } & \multirow{2}{*}{$\frac{3 \mathrm{rd}}{\mathrm{NBE}^{c} / \text { equiv. }}$} & \multirow[b]{2}{*}{$\operatorname{Ar}^{e}$} & \multirow[b]{2}{*}{$M_{\mathrm{n}}^{f} \times 10^{-4}$} & \multirow[b]{2}{*}{$M_{\mathrm{w}} / M_{\mathrm{n}}^{f}$} & \multirow[b]{2}{*}{ Yield $^{g} / \%$} \\
\hline & & $\mathrm{CL}^{c} /$ equiv. & Conc. ${ }^{d} / \times 10^{-2} \mathrm{M}$ & Time/min & & & & & \\
\hline 1 & $3.0 / 4.0 / 4.0$ & 10 & 6.36 & 50 & 25 & py & 8.9 & 1.18 & 95 \\
\hline 2 & $3.0 / 4.0 / 4.0$ & 10 & 6.36 & 50 & 25 & py & 8.8 & 1.19 & 96 \\
\hline 3 & $3.0 / 4.0 / 4.0$ & 10 & 6.36 & 50 & 25 & py & 8.8 & 1.19 & 96 \\
\hline 4 & $3.0 / 4.0 / 4.0$ & 15 & 7.27 & 50 & 25 & py & 13.4 & 1.30 & 96 \\
\hline 5 & $3.0 / 4.0 / 4.0$ & 15 & 7.27 & 70 & 25 & py & 20.8 & $2.88^{h}$ & 94 \\
\hline 6 & $3.0 / 4.0 / 4.0$ & 15 & 7.27 & 90 & 25 & py & 21.1 & $1.98^{h}$ & 92 \\
\hline 7 & $3.0 / 4.0 / 4.0$ & 15 & 7.27 & 120 & 25 & py & 23.5 & $2.09^{h}$ & 94 \\
\hline 8 & $3.0 / 4.0 / 4.0$ & 15 & 7.27 & 50 & 50 & py & 39.4 & $3.09^{h}$ & 93 \\
\hline 9 & $3.0 / 4.0 / 4.0$ & 15 & 7.27 & 50 & 50 & py & 39.1 & $3.37^{h}$ & 90 \\
\hline 10 & $3.0 / 4.0 / 4.0$ & 15 & 7.27 & 70 & 50 & py & 42.3 & $3.13^{h}$ & 91 \\
\hline 11 & $3.0 / 4.0 / 4.0$ & 15 & 7.27 & 70 & 50 & py & 41.4 & $3.42^{h}$ & 92 \\
\hline 12 & $5.0 / 4.0 / 6.0$ & 15 & 5.33 & 50 & 25 & py & 13.7 & 1.44 & 97 \\
\hline 13 & $5.0 / 4.0 / 6.0$ & 15 & 5.33 & 70 & 25 & py & 14.4 & 1.46 & 99 \\
\hline 14 & $5.0 / 4.0 / 6.0$ & 15 & 5.33 & 90 & 25 & py & 15.7 & $1.47^{h}$ & 98 \\
\hline 15 & $5.0 / 4.0 / 6.0$ & 15 & 5.33 & 120 & 25 & py & 16.9 & $1.38^{h}$ & 98 \\
\hline 16 & $5.0 / 4.0 / 6.0$ & 15 & 5.33 & 50 & 50 & py & 15.5 & $1.50^{h}$ & 93 \\
\hline 17 & $5.0 / 4.0 / 6.0$ & 15 & 5.33 & 70 & 50 & py & 16.4 & $1.60^{h}$ & 95 \\
\hline 18 & $5.0 / 4.0 / 6.0$ & 15 & 5.33 & 90 & 50 & py & 17.8 & $1.92^{h}$ & 95 \\
\hline 19 & $5.0 / 4.0 / 6.0$ & 15 & 5.33 & 120 & 50 & py & 19.0 & $1.86^{h}$ & 94 \\
\hline 20 & $11.0 / 4.0 / 5.0$ & 15 & 4.00 & 50 & 25 & py & 13.7 & 1.22 & 90 \\
\hline 21 & $11.0 / 4.0 / 5.0$ & 15 & 4.00 & 70 & 25 & py & 14.9 & 1.37 & 94 \\
\hline 22 & $11.0 / 4.0 / 5.0$ & 15 & 4.00 & 50 & 25 & $2 \mathrm{~T}$ & 15.5 & 1.33 & 88 \\
\hline 23 & $11.0 / 4.0 / 5.0$ & 15 & 4.00 & 50 & 25 & $3 \mathrm{~T}$ & 15.2 & 1.29 & 81 \\
\hline 24 & $11.0 / 4.0 / 5.0$ & 15 & 4.00 & 50 & 50 & py & 15.6 & 1.17 & 96 \\
\hline 25 & $11.0 / 4.0 / 5.0$ & 15 & 4.00 & 70 & 50 & py & 16.4 & 1.28 & 94 \\
\hline 26 & $3.0 / 4.0 / 4.0$ & 20 & 8.18 & 50 & 25 & py & 28.6 & $2.51^{h}$ & 95 \\
\hline 27 & $3.0 / 4.0 / 4.0$ & 20 & 8.18 & 50 & 25 & py & 30.7 & $2.37^{h}$ & 95 \\
\hline 28 & $3.0 / 4.0 / 4.0$ & 20 & 8.18 & 70 & 25 & py & 34.9 & $4.31^{h}$ & 98 \\
\hline 29 & $3.0 / 4.0 / 4.0$ & 20 & 8.18 & 90 & 25 & py & 28.6 & $2.19^{h}$ & 90 \\
\hline 30 & $3.0 / 4.0 / 4.0$ & 20 & 8.18 & 120 & 25 & py & 32.7 & $2.12^{h}$ & 95 \\
\hline 31 & $5.0 / 4.0 / 6.0$ & 20 & 6.00 & 50 & 25 & py & 19.4 & $1.99^{h}$ & 92 \\
\hline 32 & $5.0 / 4.0 / 6.0$ & 20 & 6.00 & 70 & 25 & py & 21.1 & $2.65^{h}$ & 94 \\
\hline 33 & $5.0 / 4.0 / 6.0$ & 20 & 6.0 & 90 & 25 & py & 24.1 & $2.05^{h}$ & 98 \\
\hline 34 & $5.0 / 4.0 / 6.0$ & 20 & 6.0 & 120 & 25 & py & 23.6 & $2.58^{h}$ & 98 \\
\hline 35 & $11.0 / 4.0 / 5.0$ & 20 & 4.50 & 50 & 25 & py & 14.9 & $1.44^{h}$ & 90 \\
\hline 36 & $11.0 / 4.0 / 5.0$ & 20 & 4.50 & 70 & 25 & py & 17.8 & $1.54^{h}$ & 91 \\
\hline
\end{tabular}

${ }^{a}$ Conditions: toluene at $25^{\circ} \mathrm{C}$ (detailed procedure, see Scheme 1). ${ }^{b}$ Amount of toluene (in gram) in each step (shown in Scheme 1). ${ }^{c}$ Equiv. to Mo. ${ }^{d}$ Calculated concentration of NBE $+\mathrm{CL}$ charged $\left(\mathrm{mmol} \mathrm{L}^{-1}\right)$ at the second stage (core formation). ${ }^{e}$ ArCHO employed for the termination $(\mathrm{py}=4$ pyridine carboxaldehyde; $2 \mathrm{~T}=2,2^{\prime}$-bithiophene-5-carboxaldehyde; $3 \mathrm{~T}=2,2^{\prime}: 5^{\prime}, 2^{\prime \prime}$-terthiophene-5-carboxaldehyde). ${ }^{f}$ GPC data in $\mathrm{THF} v s$. polystyrene standards $\left(\mathrm{g} \mathrm{mol}^{-1}\right) .{ }^{g}$ Isolated yield (\%) as $\mathrm{MeOH}$ insoluble fraction. ${ }^{h}$ Bimodal (or multi-modal) molecular weight distributions observed on GPC trace.

in Scheme 1), such as (i) the approach by increasing the $\mathrm{CL}$ under optimised conditions (Method 1, Scheme 1), (ii) the approach by reacting with CL in the co-presence of norbornene (NBE) (formation of different core size, Method 2, Scheme 2 shown below), have thus been considered. $\mathrm{Mo}\left(\mathrm{CHCMe}_{2} \mathrm{Ph}\right)(\mathrm{N}$ 2,6- $\left.{ }^{\mathrm{i}} \mathrm{Pr}_{2} \mathrm{C}_{6} \mathrm{H}_{3}\right)\left(\mathrm{O}^{t} \mathrm{Bu}\right)_{2}$ (Mo cat.) has also been chosen as the initiator due to its ability to prepare the multi-block ringopened copolymers in a precise manner with moderate propagation as well as with complete conversion of monomers. ${ }^{15,23,40-42}$ This is also due to that the initiator shows markedly higher reactivity toward strained cyclic olefins (norbornene derivatives) than the internal olefins (in the ringopened polymers). ${ }^{15,23,40-42,44} \quad 1,4,4 a, 5,8,8 a$-hexahydro-1,4,5,8exo-endo-dimethanonaphtalene $(\mathrm{CL} \text {, exo }: \text { endo }=0.15: 1.00)^{45}$ has also been chosen as the cross-linker, and the polymerisation was terminated with 4-pyridine carboxaldehyde..$^{31,34}$ The conditions for the first and the third ROMPs with NBE (4 and 15 minutes, respectively) were unchanged, because the NBE consumption should be completed based on our previous study. ${ }^{31}$ The results are summarised in Table 1.

It turned out that, as reported previously, ${ }^{31-34}$ the sequential ROMP with 10 equiv. of CL afforded ring-opened star-shaped polymers with rather low PDI values $\left(M_{\mathrm{w}} / M_{\mathrm{n}}=1.18,1.19\right.$, runs 1-3) and the results are thus reproducible. ${ }^{46}$ However, the PDI values in the resultant polymers eventually became broad if these polymerisations were conducted in the presence of 15 equiv. of CL under the same conditions $\left(M_{\mathrm{w}} / M_{\mathrm{n}}=1.30-2.88\right.$, runs 4-6); prolong the reaction time at the second (core formation) step led to increase in the $M_{\mathrm{n}}$ values with broad molecular weight distributions. Similarly, the PDI values in the 


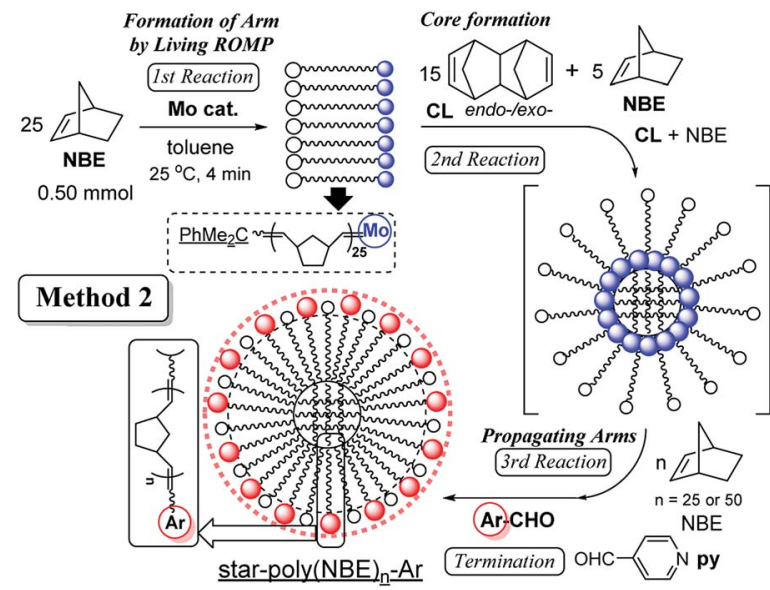

Scheme 2 Synthesis of star-shaped ROMP polymers (Method 2).

resultant polymers became broad if the polymerisations were conducted in the presence of 20 equiv. of CL under the same conditions $\left(M_{\mathrm{w}} / M_{\mathrm{n}}=2.51,2.37\right.$, runs 26,27$)$; it becomes more difficult to control the molecular weights (as well as to obtain the reproducibility).

In contrast, importantly, it turned out that the molecular weight distributions in the resultant polymers became unimodal when the polymerisation runs were conducted under diluted conditions $\left(M_{\mathrm{w}} / M_{\mathrm{n}}=1.22-1.46\right.$, runs 16-19, 20-23, Fig. 1). It should be noted that the polymerisation under high dilution (at the second step) afforded the high molecular weight star-shaped ROMP polymers with rather low PDI values $\left[M_{\mathrm{n}}=1.37 \times 10^{5}, M_{\mathrm{w}} /\right.$ $M_{\mathrm{n}}=1.22\left(\right.$ run 20); $M_{\mathrm{n}}=1.49 \times 10^{5}, M_{\mathrm{w}} / M_{\mathrm{n}}=1.37$ (run 21), shown in Fig. 1]. Moreover, further increase of NBE (in the third step) also afforded the high molecular weight ROMP polymers with rather low PDI values $\left[M_{\mathrm{n}}=1.56 \times 10^{5}, M_{\mathrm{w}} / M_{\mathrm{n}}=1.17\right.$ (run $24) ; M_{\mathrm{n}}=1.64 \times 10^{5}, M_{\mathrm{w}} / M_{\mathrm{n}}=1.28$ (run 25)]. It seems that rather

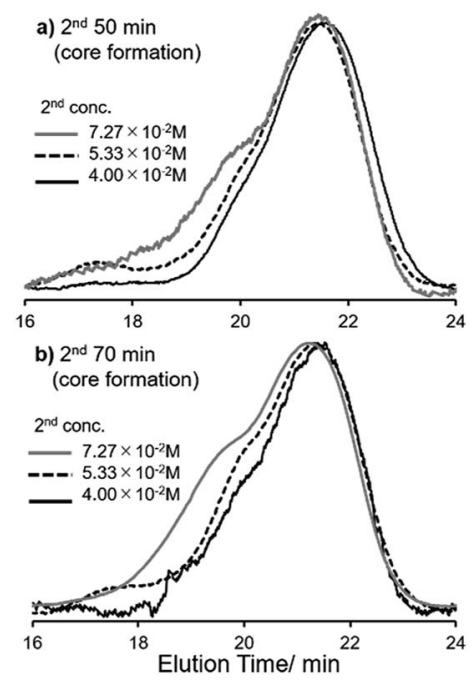

Fig. 1 Selected GPC traces of star-shaped ROMP polymers conducted under different concentration conditions, different time in the 2 nd reaction (core formation, Scheme 1 ). The reaction time (2nd step): (a) 50 min (runs 4, 12, 20, Table 1); (b) 70 min (runs 5, 13, 21, Table 1). The hights in the GPC traces were normalized. low PDI values could be maintained under high dilution conditions (runs 20,21,24,25), whereas the PDI values became rather large when the ROMPs were conducted with 50 equiv. of NBE in the third step under conditions conducted in runs 12 and $13\left(M_{\mathrm{w}}\right)$ $M_{\mathrm{n}}=1.50-1.92$, Table 1, runs 16). The results could thus probably suggest that further cross-linking (like star-star coupling upon increasing the reaction time at the second step) would be controlled under these diluted conditions (in the presence of 15 equiv. of $\mathrm{CL}$ ), which means that the monomer concentration at the core formation step seems critical for obtainment of starshaped ROMP polymers with low PDI values. The resultant polymers are soluble in toluene, tetrahydrofuran (THF), chloroform, dichloromethane (for measurement of NMR spectra and/or ordinary GPC analysis), but insoluble in methanol, ethanol, water, $n$-hexane etc. at room temperature.

Upon presence of 20 equiv. of CL, the ROMPs under high dilution conditions only afforded the star-shaped polymers with rather low PDI values, and the $M_{\mathrm{n}}$ value increased upon increasing the reaction time at the second step with broadening the distribution $\left[M_{\mathrm{n}}=1.49 \times 10^{5}, M_{\mathrm{w}} / M_{\mathrm{n}}=1.44\left(\right.\right.$ run 35), $M_{\mathrm{n}}=$ $1.78 \times 10^{5}, M_{\mathrm{w}} / M_{\mathrm{n}}=1.54$ (run 36)]. These results also suggest that certain optimisation (especially, concentration and the reaction time at the second step) should be necessary.

As shown in Table 1, the $M_{\mathrm{n}}$ values in the polymers (prepared under the optimised conditions) increased upon increasing the CL with rather low PDI values $\left[M_{\mathrm{n}}=8.9 \times 10^{4}\right.$ (run $\left.1, \mathrm{CL}=10\right)$, $1.37 \times 10^{5}($ run $20, \mathrm{CL}=15)$ or $1.49 \times 10^{5}(\operatorname{run} 21, \mathrm{CL}=15), 1.78$ $\times 10^{5}$ (run $\left.36, \mathrm{CL}=20\right)$ ], clearly suggesting that number of arms (branching) should be increasing upon increasing the amount of CL. Moreover, the $M_{\mathrm{n}}$ values also increased upon increasing amount of NBE in the third step (after formation of core), and the values are apparently higher than those in the linear ROMP polymers. The results clearly suggest that the resultant polymers are star-shaped polymers consisting of the core and arms. It also turned out that the similar polymerisations terminated with $2,2^{\prime}: 5^{\prime}, 2^{\prime \prime}$-terthiophene-5-carboxaldehyde (3T-CHO), 2,2'bithiophene-5-carboxaldehyde (2T-CHO) in place of 4-pyridine carboxaldehyde afforded the high molecular weight polymers with relatively low PDI values $\left[M_{\mathrm{n}}=1.55 \times 10^{5}, M_{\mathrm{w}} / M_{\mathrm{n}}=1.33\right.$ (run 22, terminated with 2T-CHO); $M_{\mathrm{n}}=1.52 \times 10^{5}, M_{\mathrm{w}} / M_{\mathrm{n}}=$ 1.29 (run 23, terminated with 3T-CHO)]. The results also suggest that the method can be applied to synthesis of star-shaped ROMP polymers with different end-groups.

In order to change the core size for obtainment of the starshaped ROMP polymers with more arms (branching), the reaction with CL was conducted in the co-presence of NBE (5.0 equiv.) under the optimised conditions (conducted in Table 1 under high dilution). The results (by Method 2, Scheme 2) are summarised in Table 2.

It seems that the $M_{\mathrm{n}}$ values increased upon co-presence of NBE [ex. $1.49 \times 10^{5}$ (run 21) vs. $1.53 \times 10^{5}$ (run 38)], and the difference became more significant upon addition of 50 equiv. of NBE after the core formation [third step, $1.64 \times 10^{5}$ (run 25) vs. $2.02 \times 10^{5}$ (run 40)], suggesting that the resultant polymers prepared in Method 2 possess more arm numbers compared to those in Method 1 . The resultant polymers possessed relatively low PDI values ( $\left.M_{\mathrm{w}} / M_{\mathrm{n}}=1.28-1.45\right)$, therefore, the method can 
Table 2 Synthesis of star-shaped polymers by living ring-opening metathesis polymerisation (ROMP) using $\mathrm{Mo}\left(\mathrm{CHCMe}_{2} \mathrm{Ph}\right)\left(\mathrm{N}-2,6^{-}{ }^{\mathrm{i}} \mathrm{Pr}{ }_{2} \mathrm{C}_{6}{ }^{-}\right.$ $\left.\mathrm{H}_{3}\right)\left(\mathrm{O}^{t} \mathrm{Bu}\right)_{2}\left(\right.$ Method 2) ${ }^{a}$

\begin{tabular}{|c|c|c|c|c|c|c|c|}
\hline Run & $\mathrm{CL}^{b} /$ equiv. & $\mathrm{NBE}^{b} /$ equiv. & Time/min & $\mathrm{NBE}^{b}$ equiv. & $M_{\mathrm{n}}^{c} \times 10^{-4}$ & $M_{\mathrm{w}} / M_{\mathrm{n}}{ }^{c}$ & $\operatorname{Yield}^{d} / \%$ \\
\hline 21 & 15 & - & 70 & 25 & 14.9 & 1.37 & 94 \\
\hline 37 & 15 & 5.0 & 50 & 25 & 14.5 & 1.28 & 91 \\
\hline 38 & 15 & 5.0 & 70 & 25 & 15.3 & 1.39 & 96 \\
\hline 39 & 15 & 5.0 & 50 & 50 & 19.1 & 1.36 & 98 \\
\hline 40 & 15 & 5.0 & 70 & 50 & 20.2 & 1.45 & 99 \\
\hline
\end{tabular}

${ }^{a}$ Conditions: toluene (total $20 \mathrm{~g}$, shown in runs 20-25) at $25^{\circ} \mathrm{C}$, 4-pyridine carboxaldehyde was used for the termination (detailed procedure, see Scheme 2). ${ }^{b}$ Equiv. to Mo. ${ }^{c}$ GPC data in THF vs. polystyrene standards $\left(\mathrm{g} \mathrm{mol}^{-1}\right) .{ }^{d}$ Isolated yield (\%) as MeOH insoluble fraction.

also be applied to controlled synthesis of star-shaped ROMP polymers with more branching. ${ }^{47}$

We have shown that protocols for facile and efficient synthesis of high molecular weight "soluble" star-shaped polymers with more branching (arms) have been developed by adopting the living ROMP with sequential addition of NBE and cross-linker using the molybdenum-alkylidene initiator under the optimised conditions (high dilution). The methods should provide a controlled synthesis of highly branched star-shaped ROMP polymers with different end groups (modification of the star surface), and interesting properties such as unique emission by interaction of the end group with the initiating fragment, ${ }^{33}$ supported concerted catalysts ${ }^{34}$ (by placement of different end groups/ligand or catalyst precursor) etc. can be thus highly expected. We are now exploring the possibility by introduction of various end groups into the star shaped ROMP polymers by adopting the present methods.

\section{Experimental}

\section{General procedure}

All experiments were carried out under a nitrogen atmosphere in a Vacuum Atmospheres dry-box or using standard Schlenk techniques. All chemicals used were of reagent grades and were purified by the standard purification procedures. Anhydrous grade toluene (Kanto Chemical Co., Inc.) was transferred into a bottle containing molecular sieves (mixture of 3A 1/16, 4A 1/8 and $13 \mathrm{X} 1 / 16$ ) in the drybox, and was stored over sodium/ potassium alloy, and was used after passing through an alumina short column under nitrogen flow prior to use. $\mathrm{Mo}\left(\mathrm{CHCMe}_{2} \mathrm{Ph}\right)\left(\mathrm{N}-2,6{ }^{\mathrm{i}} \mathrm{Pr}_{2} \mathrm{C}_{6} \mathrm{H}_{3}\right)\left(\mathrm{O}^{t} \mathrm{Bu}\right)_{2} \quad$ (ref. 48) and 1,4,4a,5,8,8a-hexahydro-1,4,5,8-exo-endo-dimethanonaphtalene $(\mathrm{CL}, \text { exo }: \text { endo }=0.15: 1.00)^{45}$ were prepared according to the literature. 4-Pyridinecarboxaldehyde and $2,2^{\prime}: 5^{\prime}, 2^{\prime \prime}$ terthiophene-5-carboxaldehyde (3T-CHO) and 2,2'-bithiophene5-carboxaldehyde (2T-CHO) were used in the dry-box as received (Aldrich Chemical Co.) without further purification.

Molecular weights and the molecular weight distributions of the resultant polymers were measured by gel-permeation chromatography (GPC). HPLC grade THF (Wako Pure Chemical Ind., Inc.) was used for GPC and was degassed prior to use.
GPC were performed at $40{ }^{\circ} \mathrm{C}$ on a Shimadzu SCL-10A using a RID-10A detector (Shimadzu Co. Ltd.) in THF (containing $0.03 \mathrm{wt} \%$ 2,6-di-tert-butyl-p-cresol, flow rate $1.0 \mathrm{~mL} \mathrm{~min}^{-1}$ ). GPC columns (ShimPAC GPC-806, 804 and $802,30 \mathrm{~cm} \times 8.0 \mathrm{~mm} \phi$ ) were calibrated versus polystyrene standard samples. All ${ }^{1} \mathrm{H}$ and ${ }^{13} \mathrm{C}$ NMR spectra were recorded on a Bruker AV500 spectrometer $\left({ }^{1} \mathrm{H}, 500.13 \mathrm{MHz} ;{ }^{13} \mathrm{C}, 125.77 \mathrm{MHz}\right)$, and all chemical shifts are quoted in ppm and are referenced to $\mathrm{SiMe}_{4}$. Obvious multiplicities and routine coupling constants are usually not listed, and all spectra were obtained in the solvent indicated at $25^{\circ} \mathrm{C}$.

\section{General polymerisation procedure}

Typical polymerisation procedure (run 20, Method 1, Table 1 ) is as follows. A toluene solution $(1.0 \mathrm{~g})$ containing $\mathrm{Mo}\left(\mathrm{CHCMe}_{2}-\right.$ $\mathrm{Ph})\left(\mathrm{N}-2,6{ }^{-}{ }^{\mathrm{i}} \mathrm{Pr}_{2} \mathrm{C}_{6} \mathrm{H}_{3}\right)\left(\mathrm{O}^{t} \mathrm{Bu}\right)_{2}\left(2.00 \times 10^{-5} \mathrm{~mol}\right)$ was added in one portion to a rapidly stirred toluene solution $(10.0 \mathrm{~g})$ containing the norbornene (25 equiv. to Mo) at room temperature $\left(25^{\circ} \mathrm{C}\right)$, and the solution was stirred for $4 \mathrm{~min}$. A toluene solution ( $4.0 \mathrm{~g}$ ) containing $\quad 1,4,4 a, 5,8,8 a$-hexahydro-1,4,5,8-exo-endo-dimethanonaphtalene (CL, 15 equiv. to Mo) was then added into the solution, and the mixture was stirred for prescribed time (50 $\mathrm{min})$. Then a toluene solution $(5.0 \mathrm{~g})$ containing norbornene (25 equiv. to Mo) was then added in one portion to the mixture, and the reaction solution was further stirred for $15 \mathrm{~min}$. The polymerisation was quenched by adding 4-pyridine carboxaldehyde (ca. $>10 \mathrm{mg}$, excess), and the solution was stirred for $1 \mathrm{~h}$ for completion. The mixture was then removed in vacuo until it was dissolved in the minimum amount of toluene. The solution was poured dropwise into methanol to afford pale white precipitates. The polymer was then collected by filtration and dried in vacuo. In Method 2, the basic procedure was the same except that a toluene solution containing CL and norbornene (5.0 equiv. to Mo) was added in the second step.

${ }^{1} \mathrm{H}$ NMR (in $\mathrm{CDCl}_{3}$ at $25{ }^{\circ} \mathrm{C}$ ): $\delta 5.35$ and 5.21 (br.s, $2 \mathrm{H}$ olefinic), 2.79 and 2.43 (br.s, $2 \mathrm{H}), 1.85$ and 1.03 (m, 2H), 1.78 and $1.36(\mathrm{~m}, 4 \mathrm{H}) \mathrm{ppm}$. Moreover, resonances ascribed to pyridine end group [8.54 and 8.50 (d) ppm] or oligo(thiophene) (2T, 3T, 7.00-7.40) were also observed. ${ }^{13} \mathrm{C} \mathrm{NMR} \mathrm{(in} \mathrm{CDCl}_{3}$ at $25^{\circ} \mathrm{C}$ ): $\delta$ 133.9, 133.0, 128.2, 43.1, 38.6, 33.2, 32.2 ppm. Selected NMR spectra are shown in the ESI. $\dagger$ 


\section{Conflicts of interest}

There are no conflicts to declare.

\section{Acknowledgements}

This project is supported by Grant-in-Aid for Challenging Exploratory Research (24656491, 15K14225), Japan Society for the Promotion of Science (JSPS). S. Z. acknowledges the Tokyo Metropolitan government (Tokyo Human Resources Fund for City Diplomacy) for pre-doctoral fellowship. The authors express their thanks to Profs. S. Komiya, K. Tsutsumi, and A. Inagaki (Tokyo Metropolitan Univ.) for helpful discussions.

\section{References}

1 For example, Macromolecular Engineering: From Precise Macromolecular Synthesis to Macroscopic Materials Properties and Applications, ed. K. Matyjaszewski, Y. Gnanou and L. Leibler, Wiley-VCH, Weinheim, Germany, 2007.

2 For example (ref. 2-10), N. Hadjichristidis, M. Pitsikalis, S. Pispas and H. Iatrou, Chem. Rev., 2001, 101, 3747-3792.

3 A. Hirao, M. Hayashi, S. Loykulnant, K. Sugiyama, S. W. Ryu, N. Haraguchi, A. Matsuo and T. Higashihara, Prog. Polym. Sci., 2005, 30, 111-182.

4 N. Hadjichristidis, H. Iatrou, M. Pitsikalis and J. Mays, Prog. Polym. Sci., 2006, 31, 1068-1132.

5 M. Ouchi, T. Terashima and M. Sawamoto, Acc. Chem. Res., 2008, 41, 1120-1132.

6 H. Gao and K. S. Matyjaszewski, Prog. Polym. Sci., 2009, 34, 317-350.

7 K. Matyjaszewski and N. V. Tsarevsky, Nat. Chem., 2009, 1, 276-288.

8 K. Khana, S. Varshney and A. Kakkar, Polym. Chem., 2010, 1, 1171-1185.

9 K. Matyjaszewski and N. V. Tsarevsky, J. Am. Chem. Soc., 2014, 136, 6513-6533.

10 J. M. Ren, T. G. McKenzie, Q. Fu, E. H. H. Wong, J. Xu, Z. An, S. Shanmugam, T. P. Davis, C. Boyer and G. G. Qiao, Chem. Rev., 2016, 116, 6743-6836.

11 Examples for metathesis polymerisation (ref. 11-23), M. R. Buchmeiser, Chem. Rev., 2000, 100, 1565-1604.

12 Handbook of Metathesis, ed. R. H. Grubbs, Wiley-VCH, Weinheim, Germany, 2003, vol. 3.

13 Metathesis Polymerisation, ed. M. Buchmeiser, SpringerVerlag, Berlin Heidelberg, Germany, 2005.

14 S. Hilf and A. F. M. Kilbinger, Nat. Chem., 2009, 1, 537-546.

15 K. Nomura and M. M. Abdellatif, Polymer, 2010, 51, 18611881.

16 A. Leitgeb, J. Wappel and C. Slugovc, Polymer, 2010, 51, 2927-2946.

17 M. R. Buchmeiser, Macromol. Symp., 2010, 298, 17-24.

18 H. Mutlu, L. M. de Espinosa and M. A. R. Meier, Chem. Soc. Rev., 2011, 40, 1404-1445.

19 P. Atallah, K. B. Wagener and M. D. Schulz, Macromolecules, 2013, 46, 4735-4741.
20 M. D. Schulz and K. B. Wagener, Macromol. Chem. Phys., 2014, 215, 1936-1945.

21 Handbook of Metathesis, ed. R. H. Grubbs and E. Khosravi, Wiley-VCH, Weinheim, Germany, 2nd edn, 2015, vol. 3.

22 D. J. Lunn, E. H. Discekici, J. R. de Alaniz, W. R. Gutekunst and C. J. Hawker, J. Polym. Sci., Part A: Polym. Chem., 2017, 55, 2903-2914.

23 Y. Chen, M. M. Abdellatif and K. Nomura, Tetrahedron, 2018, 74, 619-643.

24 R. S. Saunders, R. E. Cohen, S. J. Wong and R. R. Schrock, Arm (brush) first approach by addition of cross-linked reagent(s) at the final stage, Macromolecules, 1992, 25, 2055-2057, ref. 24-30.

25 J. Liu, A. O. Burts, Y. Li, A. V. Zhukhovitskiy, M. F. Ottaviani, N. J. Turro and J. A. Johnson, J. Am. Chem. Soc., 2012, 134, 16337-16344.

26 L. Liao, J. Liu, E. C. Dreaden, S. W. Morton, K. E. Shopsowitz, P. T. Hammond and J. A. Johnson, J. Am. Chem. Soc., 2014, 136, 5896-5899.

27 A. O. Burts, A. X. Gao and J. A. Johnson, Macromol. Rapid Commun., 2014, 35, 168-173.

28 J. C. Barnes, P. M. Bruno, H. V.-T. Nguyen, L. Liao, J. Liu, M. T. Hemann and J. A. Johnson, J. Am. Chem. Soc., 2016, 138, 12494-12501.

29 H. V.-T. Nguyen, Q. Chen, J. T. Paletta, P. Harvey, Y. Jiang, H. Zhang, M. D. Boska, M. F. Ottaviani, A. Jasanoff, A. Rajca and J. A. Johnson, ACS Cent. Sci., 2017, 3, 800-811. 30 Y. Shibuya, H. V.-T. Nguyen and J. A. Johnson, ACS Macro Lett., 2017, 6, 963-968.

31 Core first (in and out) approach (ref. 31-34): K. Nomura, Y. Watanabe, S. Fujita, M. Fujiki and H. Otani, Macromolecules, 2009, 42, 899-901.

32 H. Otani, S. Fujita, Y. Watanabe, M. Fujiki and K. Nomura, Macromol. Symp., 2010, 293, 53-57.

33 K. Takamizu and K. Nomura, J. Am. Chem. Soc., 2012, 134, 7892-7895.

34 K. Nomura, K. Tanaka and S. Fujita, Organometallics, 2012, 31, 5074-5080.

35 J. A. Kalow and T. M. Swager, ACS Macro Lett., 2015, 4, 12291233.

36 (reviews, ref. 36-39), S. Lubbad and M. R. Buchmeiser, Macromol. Rapid Commun., 2003, 24, 580-584.

37 M. Mayr, D. Wang, R. Kröll, N. Schuler, S. Prühs, A. Fürstner and M. R. Buchmeiser, Adv. Synth. Catal., 2005, 347, 484492.

38 M. R. Buchmeiser, in Handbook of Metathesis, ed. R. H. Grubbs, Wiley-VCH, Weinheim, Germany, 2003, vol. 3, p. 226.

39 M. R. Buchmeiser, Chem. Rev., 2009, 109, 303-321.

40 For example (ref. 40-42), R. R. Schrock, in Handbook of Metathesis, ed. R. H. Grubbs, Wiley-VCH, Weinheim, 2003, vol. 1 , p. 8 .

41 R. R. Schrock, in Metathesis Polymerisation of Olefins and Polymerisation of Alkynes, ed. Y. Imamoglu, NATO ASI Series, Kluwer Academic Publishers, 1998, pp. 1-27 and 357-380.

42 R. R. Schrock, Chem. Rev., 2009, 109, 3211-3226. 
43 The results were partly introduced in the Asian Polyolefin Workshop 2017 (APO2017), Tianjin, China, October, 2017 and the 8th International Conference on Polymer Chemistry (PC2018), Changchun, China, June, 2018.

44 For example, J. J. Murphy, H. Furusho, R. M. Paton and K. Nomura, Chem.-Eur. J., 2007, 13, 8985-8997.

45 J. K. Stille and D. A. Frey, J. Am. Chem. Soc., 1959, 81, 42734275.

46 Selected NMR spectra in the resultant polymers are shown in the ESI. $\dagger$
47 It should be noted that the polymerisation with 2 step additions [CL + NBE $(15+5.0$ equiv.) and CL (5.0 equiv.)] in the second step afforded the ROMP polymers with broad molecular weight distributions. Some of the resultant polymers became hardly soluble in toluene, tetrahydrofuran (probably due to highly cross-linking).

48 R. R. Schrock, J. S. Murdzek, G. C. Bazan, J. Robbins, M. Dimare and M. B. O'Regan, J. Am. Chem. Soc., 1990, 112, 3875-3886. 